\title{
Depression and anxiety among Grade 11 and 12 learners attending schools in central Bloemfontein
}

\author{
M A A Strydom, P J Pretorius, G Joubert \\ Department of Psychiatry, Faculty of Health Sciences, University of the Free State, Bloemfontein \\ M A A Strydom, MB ChB, MMed (Psych) \\ P J Pretorius, MB ChB, MMed (Psych) \\ Department of Biostatistics, Faculty of Health Sciences, University of the Free State, Bloemfontein \\ G Joubert, BA, MSC
}

Corresponding author: P J Pretorius (pretorpj@fshealth.gov.za)

\begin{abstract}
Objectives. Anxiety disorders are the most common childhood psychiatric disorders. Previous research suggests that South African rates may be high. Our study examined the prevalence and severity of anxiety and depression among Grade 11 and 12 learners attending schools in central Bloemfontein. Learners perceptions of the important stressors as well as the most relevant coping strategies were investigated.
\end{abstract}

Methods. A cross-sectional study was conducted by using self-assessment rating scales and questionnaires. The Hospital Anxiety and Depression Scale (HADS) was used to screen for anxiety and depressive symptoms. Participants were provided with an additional list of possible stressors and coping skills, from which they identified those applicable to themselves. All students enrolled in Grades 11 and 12 at the selected schools during August 2009 were eligible for inclusion.

Results. Five hundred and fifteen learners participated in the study, of whom $32.0 \%$ presented with moderate or severe anxiety and $5.3 \%$ with moderate or severe depressive symptoms. Mild symptoms were reported by an additional $29.0 \%$ on the anxiety subscale and $14 \%$ on the depression subscale of the HADS. Academic workload was reported as the main source of stress (81.4\%).

Conclusions. Although the study had limitations in terms of methods and size, resulting in undetermined validity, it indicated potentially higher prevalence rates for anxiety and depression than in previous South African studies and worldwide prevalence rates for adolescents. Pupils were generally hesitant to seek help from formal assistance structures provided by the schools, and preferred discussing problems with parents or friends.

SAfr J Psych 2012;18(3):84-88. DOI:10.7196/SAJP.356
The worldwide prevalence of major depression in adolescents is reported to be $4-8 \%$, and the incidence continues to increase. ${ }^{1,2}$ Very limited data on prevalence rates are currently available for South African adolescents. ${ }^{3}$ Prevalence rates for adults have been reported as $16-23 \%$ for anxiety and 10\% for major depressive disorders. ${ }^{1,4}$

Grades 11 and 12 are seen as important years for making a successful transition to adulthood and for planning one's future. Academic performance and psychosocial adjustment are important operative factors determining entrance to, and successful adjustment at, tertiary training institutions. Adolescence in general is an important period for the development of a socially integrated self-concept, while a negative self-concept may affect future decisions through depression and anxiety. ${ }^{5}$

Mood disorders have been shown to be associated with premature termination of secondary education (odds ratio (OR) 2.4), and anxiety disorders (OR 2.0) and substance abuse (OR 11.2) are significantly associated with failure to proceed to tertiary education. ${ }^{6}$ Generally, anxiety disorders have an earlier median age of onset (14 years) while depression is usually associated with onset during adulthood? Depression and anxiety during these formative years can have devastating consequences for adolescents. Depression diminishes drive, concentration and interest in pleasurable activities. It leads to disturbance in sleep and appetite, and is often associated with suicidal thoughts and hopelessness, ${ }^{8}$ which could all stand in the way of a promising future for a learner in these important school years. Anxiety can be equally debilitating, and may cause poor school performance with eventual lower educational achievement and a tendency toward substance abuse..$^{9-11}$

Although the Department of Health formulated mental health intervention strategies for adolescents, ${ }^{12}$ it is unclear whether these strategies are being properly implemented in schools. At the time 
of this study, routine screening of pupils for depression was not applied by the participating schools.

The primary aim of the study was to investigate the prevalence of depression and anxiety among Grade 11 and 12 learners. Secondary aims were to determine stress coping strategies employed by this population, and to establish whether learners made use of formal resources offered by schools in this regard.

\section{Methods}

A cross-sectional study design was used. Grade 11 and 12 learners were recruited from 4 public schools in a predominantly middleclass community in central Bloemfontein. All Grade 11 and 12 learners enrolled at these schools during August 2009 were eligible for the study. Owing to limited resources, the study was only conducted at schools using Afrikaans or English as the official medium of instruction. Learners were from one boys' school, one girls'school, and two co-ed schools.

A questionnaire designed by the investigators was used to gather information on participants' demographic details, types of stressor experienced and coping mechanisms. The Hospital Anxiety and Depression Scale (HADS) is a self-assessment scale, and a reliable screening instrument for depression and anxiety in adolescents. ${ }^{13}$ It contains 14 statements rated by selecting 1 of 4 responses that scored between 0 and 3, and 2 subscales that measure anxiety and depression, respectively. Each subscale has a maximum score of 21. Total scores of $0-7$ on the subscales are classified as normal, 8 - 11 as mild, $11-15$ as moderate, and $16-21$ as severe symptoms. ${ }^{13-15}$

To investigate a possible link with depression and anxiety, participants were also screened for at-risk drinking behaviour. The question used to screen for such behaviour was based on the United States Department of Health and Human Services Guidelines for identification of at-risk drinking behaviour. ${ }^{16}$ Learners who indicated that they consumed $\geq 4$ alcoholic drinks in 1 session (females) and $\geq 5$ (males) on $\geq 1$ occasion during the previous year, were considered at-risk drinkers. ${ }^{17}$ Questions on current and past medical, psychiatric and psychological treatment were included to separate untreated and unrecognised cases from known cases, and to detect possible influences on symptomatology.

Approval for the study was obtained from the Ethics Committee of the Faculty of Health Sciences at the University of the Free State (UFS). Permission was also obtained from the Director of Quality Assurance at the Department of Education, as well as the principals of the schools involved. Potential participants received information leaflets and consent forms at their schools. They were requested to hand these documents to their parents to obtain consent. Contact details were provided should parents or learners have questions before and after the study. Only those learners for whom written parental consent as well as personal assent could be obtained, were allowed to participate in the study.
Learners were informed that participation in the study was voluntary and anonymous, and that personal information would be kept strictly confidential and could not be linked to any specific individual. Questionnaires were completed in the beginning or at the end of certain classes (determined by each school), and completed questionnaires were placed into sealed boxes by the learners to ensure confidentiality.

To obtain feedback regarding the questionnaire before proceeding with the study, a pilot study was conducted using 5 scholars in the same age group as the participants, but who were not attending the schools included in the study.

Statistical data analyses were facilitated by the Department of Biostatistics at UFS. Frequencies and percentages were used to summarise results, and subgroup comparisons were done using 95\% confidence intervals ( $\mathrm{Cls}$ ) for differences in percentages or means. Fisher's exact tests or chi-square tests were used where applicable.

\begin{tabular}{|c|c|}
\hline Demographic variable & Percentage of learners $(N=515)$ \\
\hline \multicolumn{2}{|l|}{ Age (years) } \\
\hline 16 & 16.1 \\
\hline 17 & 46.0 \\
\hline 18 & 31.7 \\
\hline$>18$ & 6.2 \\
\hline \multicolumn{2}{|l|}{ Gender } \\
\hline Male & 29.7 \\
\hline Female & 70.3 \\
\hline \multicolumn{2}{|l|}{ Grade } \\
\hline Grade 11 & 52.4 \\
\hline Grade 12 & 47.6 \\
\hline \multicolumn{2}{|l|}{ Race } \\
\hline Black & 53.6 \\
\hline White & 35.2 \\
\hline Coloured & 7.6 \\
\hline Asian & 2.3 \\
\hline Indian & 1.2 \\
\hline Other & 0.2 \\
\hline \multicolumn{2}{|l|}{ Home language } \\
\hline Afrikaans & 29.5 \\
\hline English & 15.3 \\
\hline Sesotho & 24.3 \\
\hline Setswana & 19.1 \\
\hline isiXhosa & 6.4 \\
\hline Other & 4.1 \\
\hline Mixed & 1.2 \\
\hline
\end{tabular}


Table 2. Anxiety and depression scores of Grade 11 and 12 learners expressed in percentage of learners per category

\begin{tabular}{llllll}
\hline & \multicolumn{2}{c}{ HAD-A (anxiety) } & & \multicolumn{2}{c}{ HAD-D (depression) } \\
\cline { 2 - 3 } HAD scores & Grade $\mathbf{1 1}(\boldsymbol{n}=\mathbf{2 7 0})$ & Grade $\mathbf{1 2}(\boldsymbol{n}=\mathbf{2 4 5})$ & & Grade 11 ( $\boldsymbol{n = 2 7 0 )}$ & Grade 12 (n=245) \\
\hline $0-7$ (normal) & 42.8 & 34.6 & 84.2 & 76.2 \\
$8-10$ (mild) & 27.3 & 31.3 & 11.7 & 17.2 \\
$11-14$ (moderate) & 22.7 & 25.1 & 3.8 & 5.7 \\
$15-21$ (severe) & 7.2 & 9.1 & 0.4 & 0.8
\end{tabular}

\section{Results}

Of the 1513 consent forms handed out, 583 were returned with parents giving consent, while 2 were returned refusing consent. Of the 583 questionnaires handed out, 562 were completed. Response rates for returned and signed consent forms were 38.3\%, 75.8\%, $29.2 \%$ for the schools included in the analysis. The boys' school had a low response rate $(10.1 \%)$ and was excluded from the analysis. Consequently, a total of 515 questionnaires were analysed. The demographic data of the respondents are summarised in Table 1 showing that $70.3 \%$ of participants were girls, and $53.6 \%$ were black.

The prevalence rates of anxiety (HAD-A $\geq 8$ ) and depression (HAD$D \geq 8$ ) were $61.2 \%$ and $19.7 \%$, respectively. The prevalence of anxiety was 57.2\% among Grade 11 learners and 65.4\% among Grade 12 learners. Depressive symptoms were present in $15.9 \%$ and $23.8 \%$ of Grade 11 and 12 learners, respectively (Table 2). The mean scores for both the anxiety and depression subscales were significantly higher among learners in Grade 12. Mean scores of 8.5 for Grade 11 and 9.2 for Grade 12 were recorded on the anxiety subscale ( $p=0.0313,95 \%$ $\mathrm{Cl}-1.4$ - -0.1). The mean scores for the depression subscale were 4.5 and 5.4 for Grade 11 and 12 learners, respectively $(p=0.0019,95 \% \mathrm{Cl}$ $-1.4--0.3)$. The prevalence of anxiety was $52.9 \%$ and $49.4 \%$ among male Grade 11 and 12 learners, respectively ( $p=0.6706$ ), compared with 58.8\% and $73.2 \%$ among female Grade 11 and 12 learners, respectively $(p=0.0043)$. For males, the prevalence of depression was $18.3 \%$ and $20.2 \%$ in the Grade 11 and 12 learners, respectively $(p=0.7635)$, compared with $14.9 \%$ and $25.4 \%$ in the female Grade 11 and 12 learners, respectively $(p=0.0128)$.

Of the options provided on the questionnaire, the most important reported source of stress was schoolwork (81.4\%), followed by uncertainty about the future or future plans (77.8\%). Relationships with teachers contributed the least to stress, with only $12.1 \%$ of learners regarding this as stressful (Table 3). Participants reported discussing a problem with someone whose opinion they valued as the most commonly used stress coping strategy (74.2\%). Approximately 49\% indicated that they discussed problems with friends, while $38 \%$ indicated that they discussed problems with their mother, $12.4 \%$ with their father and $43.1 \%$ indicated 'other'. Among the latter, problems were discussed with a friend (49\%), a sister (13.2\%), and more than one person (6.2\%). Only 3.5\% specified that they spoke to a psychologist, with $2.3 \%$ indicating the school psychologist.

\begin{tabular}{lc}
$\begin{array}{l}\text { Table 3. Stressors identified by Grade } \\
\text { as sources of anxiety and depression }\end{array}$ \\
\hline Stressor & Percentage of learners ( $\mathbf{N = 5 1 5 )}$ \\
\hline Schoolwork & 81.4 \\
Future plans & 77.8 \\
Relationship with parents & 43.1 \\
Situation at home & 43.0 \\
Love relationship & 36.7 \\
Relationship with friends & 31.6 \\
Relationship with teachers & 12.1 \\
Other & 8.6
\end{tabular}

Socialising with friends was the second most commonly applied coping strategy (73.6\%). Taking a substance to cope was indicated by $27.6 \%$ of the learners, of whom $10.9 \%$ used alcohol, $10.2 \%$ cigarettes, and 3.7\% cannabis. Approximately $9 \%$ of participants used medication prescribed by a doctor for stress-related conditions.

Forty-nine per cent of learners screened positively for at-risk drinking behaviour. Of these, 32.2\% fulfilled the criteria for at-risk drinking behaviour on one occasion only, while $38.0 \%$ exceeded at-risk drinking criteria on $\geq 4$ occasions during the past year. Of the Grade 11 and 12 learners, 44.4\% and 54.8\%, respectively, were at-risk drinkers. The association between grade and at-risk drinking was significant $(p=0.0206)$. The relative risk of Grade $12 \mathrm{v}$. Grade 11 was 1.23 (95\% Cl 1.03; 1.47). For males, the relative risk for at-risk drinking among Grade 12 v. Grade 11 learners was 1.16 (95\% Cl 0.80 - 1.69), and for females 1.24 (95\% Cl 1.01 - 1,51). No significant association was observed between at-risk drinking and severity of anxiety $(p=0.2047)$ and severity of depression $(p=0.1437)$.

As far as treatment was concerned, $4.8 \%$ of learners said they were receiving treatment for stress at the time of the study, while $6.4 \%$ were taking medication prescribed by a doctor for a psychiatric condition. Of those learners with moderate or severe anxiety (HADA score $\geq 11), 87.6 \%$ were not taking any medication for a psychiatric condition, and of those with an HAD-D score $\geq 11,81.5 \%$ were not on any medication for a psychiatric illness. Eighty-seven per cent of the learners were writing a test or exam in the 2 weeks following the study. 


\section{Discussion}

The results show that a substantial number (61.2\%) of Grade 11 and 12 learners were suffering from anxiety to varying degrees. These values were much higher than the adult prevalence of anxiety in South Africa, which has been reported as 23\%.' The prevalence of depression among learners was not as high (19.7\%) but it did, however, occur to such an extent that it could be regarded as cause for concern, and was higher than the 10\% prevalence of depression among South African adults.' From the information acquired, we concluded that most of these learners were not receiving treatment for these conditions, possibly owing to not being detected. Anxiety, especially if untreated, may eventually lead to depression, substance abuse and educational underachievement. ${ }^{18}$

Our study results indicate that learners preferred discussing problems with peers, rather than parents, teachers or school psychologists. This may be due to concerns about confidentiality or possible stigmatisation. It is also possible that pupils are unaware of psychological support offered by schools. Mostert and Loxton have reported a significant reduction of anxiety symptoms by means of peer-support programs. ${ }^{19}$

A possible link between at-risk drinking behaviour and depression or anxiety was not supported by our findings. However, our results were similar to findings of other researchers who reported a disconcerting level of acceptance among teenagers for excessive alcohol consumption. The Centers for Disease Control and Prevention (CDC) 20 in the USA reported that $19 \%$ of high school pupils were binge drinking in the 30 days preceding the study. Direct comparisons between our study and that of the CDC are not possible as different criteria for excessive alcohol use were applied. Excessive drinking in adolescents had, apart from potentially serious psychosocial consequences, been linked to cognitive deficits, changes in brain development, poor school performance and increased risk for suicide attempts. ${ }^{21,22}$

The effect of mental disorders on adolescents has been shown to reduce educational achievement in many countries, including South Africa. Myer et al. ${ }^{9}$ previously reported an increased risk of failing to complete secondary school in the presence of any anxiety disorder (OR 1.1) and depression (OR 1.7). If left untreated, these disorders can have far-reaching consequences on a personal level as well as on national education outcomes. Education departments and schools need to identify and assist at-risk learners as early as possible. With most learners reporting the volume of schoolwork and future plans as their biggest stressors, it could be asked whether certain aspects of the school curriculum need to be scrutinised, or whether stress management skills need to be included in student education. According to Da Costa and Mash, ${ }^{1}$ struggle with academic workload was also found to be the biggest stressor in adolescents with anxiety and depression.

Our study has some limitations. The data rely on the response accuracy of the pupils (who hopefully took the questionnaire seriously), although we cannot exclude false-positive results. Parental consent had to be obtained before questionnaires could be completed, and therefore it might be that consent was refused or not brought back to school in children with known mental illness. It is also possible that pupils with no psychological symptoms were less inclined to complete the questionnaire. The exclusion of one school from the analysis meant that study participants were predominantly female (70.3\%), which could in part explain the high rates of anxiety and depression in this study. Results could therefore not be generalised to the South African adolescent population. The majority of participants (86.7\%) confirmed that they were writing tests or exams within 2 weeks of completing the questionnaires. Although most schools write tests weekly, this factor needs to be taken into account when interpreting these results. As this was a cross-sectional study, we cannot determine whether these results would vary over time.

\section{Conclusion}

Although these results are of undetermined validity and cannot necessarily be generalised, they do seem to indicate excessively high rates of anxiety and depression among learners in Bloemfonteinbased secondary schools.

A need for stress awareness programmes, early identification and improved access to mental health support services was identified. Our study suggests that interventions should consider empowering pupils with the means to detect possible mental problems in peers and educate them on ways to support peers and assist them in obtaining professional help when indicated.

Acknowledgements. We thank Drs A Groenewoud, W van der Nest and $L M$ van der Merwe for assistance with translation; Dr U S Viljoen for general support; Sandra Brown for assistance with typing; school principals and teachers for their assistance; and especially the learners for their willingness to participate in the study. Dr D Struwig is acknowledged for technical and editorial preparation of the manuscript for publication.

\section{References}

1. Da Costa LC, Mash B. A description of the psychosocial factors associated with depression and anxiety in South African adolescents attending urban private practices in Johannesburg. South African Family Practice 2008;50:51.

2. Birmaher B, Ryan ND, Williamson DE, et al. Childhood and adolescent depression: a review of the past 10 years. Part 1. J Am Acad Child Adolesc Psychiatry 1996;35:1427-1439.

3. Kleintjes S, Flisher AJ, Fick M, et al. The prevalence of mental disorders among children, adolescents and adults in the Western Cape, South Africa. South African Psychiatry Review 2006;:157-160.

4. Herman AA, Stein DJ, Seedat S, Heerenga SG, Moomal H, Williams DR. The South African Stress and Health (SASH) study: 12-month and lifetime prevalence of common mental disorders. S Afr Med J 2009;99:339-344.

5. Sebastian C, Burnet S, Blakemore SJ. Development of the self-concept during adolescence. Trends Cogn Sci 2008;12:441-446.

6. Bruffaerts RP, Bonnewyn A, Demyttenaere K. Associations between early-onset mental disorders and educational attainment in Belgium: A population study. Tijdschr Psychiatr 2010;52:133-142.

7. Bonnewyn A, Bruffaerts R, Vilagut G, Almansa J, Demyttenaere K. Lifetime risk and ageof-onset of mental disorders in the Belgian general population. Soc Psychiatry Psychiatr Epidemiol 2007:42:522-529. 
8. American Psychiatric Association. Diagnostic and Statistical Manual of Mental Disorders. 4th ed. Text Revision. DSM-IV-TR. Washington, DC: American Psychiatric Association, 2000.

9. Myer L, Stein DJ, Jackson PB, Herman AA, Seedat S, Williams DR. Impact of common mental disorders during childhood and adolescence on secondary school completion. S Afr Med J 2009;99:354-356.

10. Mazzone L, Ducci F, Scoto MC, Passaniti E, D'Arrigo VG, Vitiello B. The role of anxiety symptoms in school performance in a community sample of children and adolescents. BMC Public Health 2007;7:347

11. Deas D, Thomas S. Comorbid psychiatric factors contributing to adolescent alcohol and other drug use. Depression 2002;26:116-121.

12. Department of Health, South Africa. Policy Guidelines on Child and Adolescent menta health. http://www.info.gov.za/view/DownloadFileAction?id=94167 (accessed 3 May 2009).

13. White D, Leach C, Sims R, Atkinson M, Cottrell D. Validation of the Hospital Anxiety and Depression Scale for use with adolescents. Br J Psychiatry 1999;175:452-454.

14. Zigmond AS, Snaith RP. The Hospital Anxiety and Depression Scale. Acta Psychiatr Scand $1983 ; 67: 361-370$
15. Snaith RP. The Hospital Anxiety and Depression Scale. Health Qual Life Outcomes 2003;1:29. 16. Department of Health and Human Services, National Institutes of Health, USA Government. Helping patients who drink too much: a clinician's guide. http://pubs.niaaa.nih.gov/ publications/Practitioner/CliniciansGuide2005/guide.pdf (accessed 12 July 2007).

17. Smith PC, Schmidt SM, Allensworth-Davies D, Saitz R. Primary care validation of a singlequestion alcohol screening test. J Gen Intern Med 2009;24:783-788.

18. Woodward $L$, Fergusson DM. Life course outcomes of young people with anxiety disorders in adolescence. J Am Acad Child Adolesc Psychiatry 2001;40:1086-1093.

19. Mostert J, Loxton $\mathrm{H}$. Exploring the effectiveness of the FRIENDS program in reducing anxiety symptoms among South African children. Behaviour Change 2008:25:85-96.

20. Centers for Disease Control and Prevention (CDC). Alcohol use among high school students - Georgia, 2007. MMWR Recomm Rep 2009;58:885-890.

21. Miller JW, Naimi TS, Brewer RD, Jones SE, Binge drinking and associated health risk behaviors among high school students. Pediatrics 2007;119:76-85.

22. Centers for Disease Control and Prevention (CDC). Alcohol and Public Health fact sheets - underage drinking. http://www.cdc.gov/Alcohol/fact-sheets/underage-drinking.htm (accessed 20 July 2011). 